\title{
CHINA'S URBAN EFFICENCY EVALUATION ANALYSIS UNDER THE RESTRICTION OF ENVIRONMENT
}

\author{
Yuan Xiaoling and He Bin* \\ School of Finance and Economics of Xi'an Jiao Tong University, Xi'an, Shaanxi, China
}

Given the fact that the existing evaluation and analysis of urban efficiency are negligent of external negative effects on the environment in the medium and long term, this paper constructs an SBM - an undesirable model containing an undesirable output, measures the urban efficiency of 285 cities in China at or above the prefecture level during 2003-2012, decomposes it into urban pure technical efficiency and urban scale efficiency and makes a comparative analysis of them separately. The results show that, when the environmental factors are taken into account, the level of urban efficiency in China is low, but is a large room for it to improve. The impact of the decomposition of urban scale efficiency on urban efficiency is continuously enhancing. From a regional perspective, urban pure technical efficiency is the highest in the eastern region, only to be followed by the western region, whereas it is the lowest in the middle region. From the point of view of the scale, urban pure technical efficiency represents a "U-type" change and urban scale efficiency represents an „inverted $U^{\prime \prime}$ change. Therefore, this paper suggests that in order to improve urban efficiency, we should adopt different urban development policies for cities located in different regions and on different scales.

Keywords: urban efficiency, SBM Model, difference analysis

\section{INTRODUCTION}

Since the Reform and the Opening, China's urban development has experienced a period of rapid development both quantity and scale ones, and great changes have taken place. By the end of 2013, the number of China's urban resident population reached 730 million, the urbanization rate increased to $53.73 \%$, the number of cities (at the prefecture level

\footnotetext{
* Correspondence to: H. Bin, School of Finance and Economics of Xi'an Jiao Tong University, No.74 The West Yanta Road, Xi'an, Shaanxi, China; e-mail: 245283162@qq.com
}

and above it) reached 286. At the same time, the urban economy became an important bearer of China's economic growth. For example, the three largest urban agglomerations, namely Beijing-Tianjin-Hebei, the Pearl River Delta and the Yangtze River Delta, account for a proportion of the GDP reaching $36 \%$. At the same time, it was also noticed that the development of Chinese urban efficiency was facing serious problems: an extensive expansion of urban resources, accompanied by a serious waste of land resources; the urban management level is low, leading to a serious "urban disease"; the worsening ecological pollution of the environment. Since the $18^{\text {th }}$ CPC National Congress 
proposed an „intensive, smart, green, low-carbon model of the urbanization road", the high quality and efficiency of urban construction is the inevitable choice of new urbanization in China. Therefore, it is necessary that a comprehensive analysis of China's urban efficiency level and change, a spatial layout, should be conducted, providing a theoretical support and the policy suggestion to improve the quality of urban construction.

The studies of urban efficiency started relatively late, when domestic and international scholars conducted in-depth researches in the thot issues of urban efficiency. In the study of urban efficiency, early scholars used a single indicator to measure efficiency, such as the efficiency of labor efficiency, and used it to study the relationship between urban efficiency and the size of a city (Alonso, 1971, 71-83; Prud'home \& Lee, 1999, 1849-1858). In his further research into the matter, W. D. Macmillan (1986) first proved that the DEA model could be applied to evaluate the behavior of a regional output, and A. Charnes, W. Coper and S. Li (1989) first used the DEA model to analyze the efficiency of the economic development of 28 Chinese cities in 1983-1984, not only confirming that the DEA is a viable approach to urban studies, also proposing additional output indicators such as the quality of life that should be included in an urban efficiency assessment in order to carry out a more comprehensive assessment of urban development. Later, different scholars used this method to evaluate urban efficiency from different research aspects (Byrnes \& Storbeck, 2000; Syrjänen, 2004, 20-33; Poveda, 2012, 343-366; Staničková \& Skokan, 2012, 349-357).

Domestic scholars also did research into urban efficiency, the earliest one being able to trace back to $\mathrm{Li}$ Bozhi (1987, 115-121+128) doing research in the economic efficiency of a city, urban residential efficiency, urban operation efficiency, urban environmental efficiency, as the four parts for the evaluation of the efficiency of Nanchang City. After this, scholars did research into the development of urban efficiency following two routes: the first one was researching in the methods of improving. There was a transition from a single index sorting out a multiple index comprehensive evaluation (Wang Sijun, 1994, 46-52), the traditional DEA model (Gao Chunliang, 2006, 36-42; Li Pei, 2007, 97-106; Dai
Yong'an, 2010a), the super DEA model (Yuan Xiaoling, Zhang Baoshan \& Zhang Xiaoni, 2008, 102-107), and the SFA model (Dai Yong'an, 2010b, 103-117+132) as well as other methods, gradually improving the accuracy of the urban efficiency evaluation of China; the second one implied that the object of studying continued to expand and improve, from the singlecity to a provincial- or regional-level economy only to move on to the national level. There are some scholars who studied the efficiency of the professional features of the city (Fu Juan \& Sun Jiuwen, 2014, 31-38; Zhang Juntao \& Liu Jianguo, 2011, 578-583+590; Pan Jinghu \& Yin Jun, 2012, 53-60; Li Xun, Xu Xianxiang \& Chen Haohui, 2005, 615-625; Zhao Xiaoxia, Qu Aixue, Xun Wenhua \& He Leilei, 2012, 74-78).

By reviewing the study of the literature found in the existing urban efficiency measurement study most studies only use economic efficiency characterizing urban efficiency, neglected in the production process of urban life rubbish and industrial waste discharge and other environmental negative outputs, for which reason it is difficult to accurately scientifically evaluate urban efficiency, consider the environmental factors which may vary urban efficiency. In view of this, this paper will use the SBM Undesirable Model, which contains the negative output of the city's environment in the operation process in order to reasonably determine urban efficiency, explore the spatial characteristics of the evolution of China's urban efficiency and put forward some methods to improve the efficiency of urban system. For the construction and development of new urbanization in China, a reasonable and scientific reference is put forward.

\section{RESEARCH METHODS AND DATA COLLECTION}

\section{Research methods}

This paper uses the Tone proposed, considering the undesirable outputs of the SBM-Undesirable Model of a Chinese prefecture-level city as an independent decision making unit (DMU) in order to more accurately measure the urban efficiency under environmental constraints. The principle is as follows: 
Assuming the urban system with a total of $\mathrm{N}$ decisionmaking units, each decision-making unit has three vectors namely the input, the expected output and the undesirable output, which are as follows: $x \in R^{m}, y^{g} \in R^{S_{1}}, y^{b} \in R^{S_{2}}$. The Defined matrix $X, Y^{g}$, $Y^{b}$ is as follows:

$X=\left[x_{1}, \ldots, x_{n}\right] \in R^{m \times n}>0$

$Y^{g}=\left[y_{1}^{g}, \ldots, y_{n}^{g}\right] \in R^{S_{1} \times n}>0$

$Y^{b}=\left\lceil v_{1}^{b}, \ldots, v_{.}^{b}\right\rceil \in R^{S_{2} \times n}>0$

Then, the production possibilities set $\mathrm{p}$ is defined as:

$P=\left\{\left(x, y^{g}, y^{b}\right) \mid x \geqslant X \lambda, y^{g} \leqslant Y \lambda, \lambda \geqslant 0\right\}$

Then, by definition, the undesirable output of the SBMUndesirable model is added as follows (1):

$$
\begin{aligned}
& \rho=\min \frac{1-\frac{1}{m} \sum_{i=1}^{m} S_{i}^{-} / X_{i 0}}{1+\frac{1}{S_{1}+S_{2}}\left(\sum_{r=1}^{S_{1}} S_{r}^{g} / Y_{r 0}^{g}+\sum_{l=1}^{S_{2}} S_{1}^{b} / Y_{l 0}^{b}\right)} \\
& \text { s.t. }\left\{\begin{array}{l}
X_{0}=X \lambda+S^{-}, \quad Y_{0}^{g}=Y^{g} \lambda-S^{g}, \quad Y_{0}^{b}=Y^{b} \lambda+S^{b} \\
S^{-} \geqslant 0, S^{g} \geqslant 0, S^{b} \geqslant 0, \lambda \geqslant 0
\end{array}\right.
\end{aligned}
$$

In the above formula vector $S^{-}, S^{g}, S^{b}$ corresponding, respectively, to the input slack and the desired output slack and the undesirable output slack. $\lambda$ is the weight vector; $\rho$ is the target value of efficiency, and is strictly monotone, satisfying $0 \leq \rho \leq 1$. When $\rho=1$ and $S^{-}=0$, $S^{g}=0, S^{b}=0$ the decision-making unit is effective; if $\rho<1$, the decision-making unit is ineffective, so it is necessary that improvements should be made with respect to the input and the output.

According to the literature, in the urban efficiency analysis, it is decomposed into pure technical efficiency and scale efficiency. The formula is expressed as:

$T E=P T E \times S E$

Pure Technical Efficiency (PTE) reflects the degree or the level of the existing technology which is used by urban production and embodies the fact that the input of urban elements can obtain a degree which the technological capability plays at the corresponding output level. The higher pure technical efficiency is, the higher management level and the higher production level of urban development are, which is an important foundation for the conducting of a city's efficiency. Scale Efficiency $(S E)$ reflects the agglomeration effect of a city that plays a role of a social and an economic activity and the effective degree of the input and output scales, so a moderate scale is an important factor in the achievement of a city's efficiency.

\section{The research sample}

China adopted the "city governing county" system, the prefecture-level city and cities which are above the prefecture level as a political, economic and cultural center of the region, with strong representatives, so the object of studying in this paper is the prefecture-level city and the cities which are above the prefecture level. By 2013, there had been a total of 289 cities in China that were prefecture-level cities and cities which are above the prefecture level. According to the availability of the city-related data, a total of 285 cities have been selected (excluding Lhasa, Sansha, Tongren City, Bijie City, not including Hong Kong, Macao and Taiwan regions) as the research subjects, these sample cities accounted for $98.61 \%$ of the total number of the prefecture-level cities and the cities which are above the prefecture level in our country. In the eastern, the central and the western regions there are 101, 100 and 85 cities, respectively. We have selected to research into the period from 2003 to 2012, with a total of 2850 observation results.

\section{Data sources and processing}

Input indicators: Select land, labor and capital as input indicators respectively represented by an urban builtup area, a number of employees of the secondary and the tertiary industries of municipal districts and a fixed capital stock. The existing data can only make it possible for us to obtain the volume of investment in the fixed assets of each city in a particular year, but the current capital corresponds to a certain output in the current period, which can also be used in the lag period corresponding to the corresponding output; Therefore, we have used the perpetual inventory 
method in order to calculate the capital stocks of the 285 cities nationwide. The calculating formula is: $K_{i t}=K_{i t-1}(1-\delta)+I_{i t}$, where $\delta$ is the depreciation rate, $I_{i t}$ is the actual fixed-asset investment of the i-th city in that year. In the base year, in order for us to make a calculation of the capital stock, we have used the method by A. Young's (2000), using the total fixed assets investment in the base year divided by $10 \%$ to represent the initial capital stock, and we have used a $10.96 \%$ depreciation rate which was used by Shan Haojie (2008, 17-31) to calculate the capital stock of our country.

The expected output: Based on the purpose of this research, we have selected indicators from economic, social and ecological benefits as the three aspects in order to measure the output of the city, respectively represented by the added value of the secondary and the tertiary industries, the total social retail amount of municipal districts and the urban green area. The added value of the secondary and the tertiary industries of each individual city is adjusted to the price of 2003, by the GDP deflator of each particular year in their province. The total retail amount of social consumer goods in the municipal districts is selected so as to represent the output indicators of social welfare, in which the total retail sales are adjusted to the price of 2003 by using the consumer price index, this index mainly reflecting a change in the urban residents' living standards. New urbanization development needs a good ecological environment and living conditions, so we have selected the urban green area to represent the output indicators of ecological benefits.

The undesirable output: Industrial wastewater, industrial waste gas and solid waste can be seen as a process of economic development, intuitively expressing the negative externalities of human activities with respect to the environment; however, due to the limitations of obtaining data, now we mainly take the indicators such as a discharge amount of industrial waste water and a discharge amount of industrial gas as the characteristic ones for environmental pollutant discharge. The relevant data presented in this section were all obtained from the China City Statistical Yearbook of the past years.

\section{AN EMPIRICAL ANALYSIS OF URBAN EFFICIENCY}

\section{The whole change of urban efficiency}

By applying the MaxDEA Pro5.2 software to calculate the above data, it is possible to obtain the urban efficiency of each year from 2003 to 2012, the results of which are accounted for in Table 1. In this paper, average urban efficiency is 0.381 , which was calculated by the software.

During the measurement period, the number of the cities in the efficient frontier hyperplane reached its maximum in the year 2006, which is 30 , accounting for $10.53 \%$ of all of the observed sample cities. The cities whose efficiency was mainly effectively achieved belong to the following categories, including Beijing, Shanghai, Guangzhou and Shenzhen, these are the cities with highly-developed economies, and guide an influx of large capital and labor, urban modernization and good internationalization development, which can effectively improve urban efficiency. Represented by Changsha, Wuhan, Xiamen and the other cities of the regional urban agglomeration central city. Foshan, Dongguan, Zhongshan and the other cities in the

Table 1 2003-2012 The mean of the national urban efficiency changes

\begin{tabular}{l|lllllllllll}
\hline & 2003 & 2004 & 2005 & 2006 & 2007 & 2008 & 2009 & 2010 & 2011 & 2012 & Mean \\
\hline Urban Efficiency & 0.41 & 0.41 & 0.41 & 0.46 & 0.43 & 0.37 & 0.24 & 0.38 & 0.35 & 0.37 & 0.38 \\
Pure Technical Efficiency & 0.50 & 0.51 & 0.50 & 0.53 & 0.53 & 0.47 & 0.31 & 0.51 & 0.51 & 0.53 & 0.49 \\
Scale Efficiency & 0.83 & 0.80 & 0.83 & 0.87 & 0.80 & 0.77 & 0.81 & 0.73 & 0.70 & 0.70 & 0.78 \\
\hline
\end{tabular}

Source: Authors 
Pearl River's Delta are also included, internal through an organic integration, so they have a high urban collaborate degree and effectively improve urban efficiency; the rest of the cities are mostly a single industrial structure of the resource-based cities, such as the city of Daqing, Ordos, Hohhot, Suihua etc., which are in the northern area, and Yuxi City, that is in Yunnan Province, Karamay in Xinjiang Province and the other cities. The number of the cities belonging to the efficient frontier hyperplane reached its minimum in the year 2011, with no more than 22 cities in the efficient frontier hyperplane, with a proportion dropping to $7.72 \%$. There is a larger impact of the cities which are mainly located in the region of the Pearl River's Delta, namely the manufacture-based cities and the resource-based cities of Suihua, Karamay, Yuxi.

Based on the analysis presented in Figure 1, which shows the mean trends of urban efficiency in our country, we can divide China's urban efficiency change into the following three stages:

- The first stage: from 2003 to 2007. During this period, the national urban efficiency stably fluctuated at the level of 0.42 , and reached the maximum in 2006, the possible reason for this being is the fact that since China had joined the WTO, as the world's factory, plenty of cheap labor and resources attracted a lot of foreign capital to flow into China, thus promoting rapid economic development. The cities also had rapid development, although the extensive mode of the process of urban development led to an excessive consumption of resources and an increase in environmental pollution. All the regions constructed industrial parks and expanded their city-scales, resulting in the low efficiency of the use of land, which also reduced urban efficiency.

- The second stage: from 2008 to 2009. Urban efficiency dropped substantially, and rebounded in 2009, after having reached the lowest value. With the emergence of the worldwide economic crisis in 2008, international trade volumes declined, making the economic indicators characterizing the decline in the desirable output during the operation of the city, resulting in the decline in urban efficiency. During 2009, thanks to a stimulating 4-trillion-worth investment by the Central Government, a large number of fixed asset investment projects were quickly launched throughout the country, there was an asset investment redundancy, and the economic output did not increase in the short term, thus causing a rapid decline in urban efficiency.

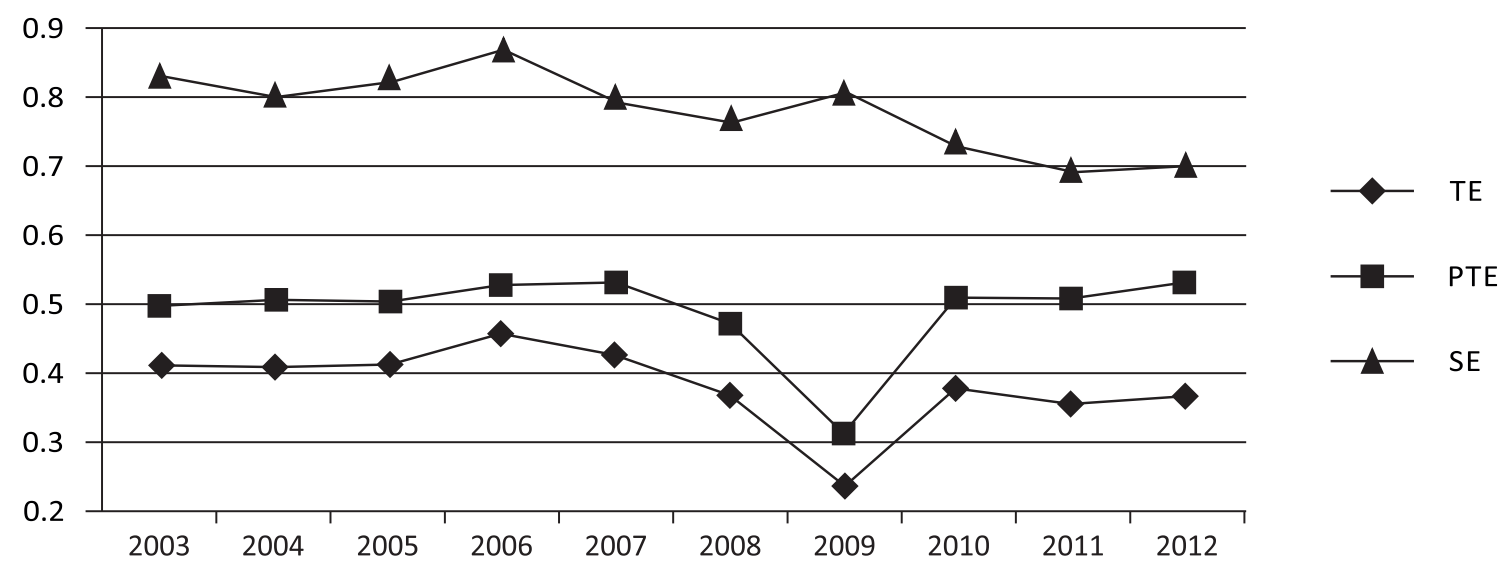

Figure 1 The national urban efficiency change trend 
- The third stage: from 2010 to 2012. Urban efficiency rebounded. Under the guidance of the policy of 2010, the policy effects appeared. There were a large number of infrastructural constructions, which gradually led to an increase in the industrial output, while the overall economy maintained steady production. But, this economic recovery still relied on the traditional industries, resulting in overcapacity, resource consumption, environmental damage and other issues, which did not make a substantial increase in the urban efficiency of our country, but rather restored to its original level. The people's awareness of the environment and environmental issues was gradually awakening, putting forward the fact that the transformation of economic development could improve urban efficiency from nature.

Urban efficiency by the decomposition of pure technical efficiency and scale efficiency, the results of which are shown in Table 1, on the basis of the change of the value accounted for in Table 1, shows that the mean of the national pure technical efficiency was 0.489 during 2003-2012, which was slightly higher than urban efficiency. The mean of the national scale efficiency was 0.783 . From the point of view of trends, pure technical efficiency change exhibits the same change in trend as comprehensive efficiency does, and overall scale efficiency shows a declining trend, the mean of scale efficiency ranging from 0.83 , in 2003, only to fall to 0.70 in 2012, which was a decline of 15.66 percent, and the average annual decline was $1.57 \%$.

On the basis of decomposition, in order to better understand the impact of the pure technical efficiency and the scale efficiency of the Chinese cities above the prefecture level on urban efficiency, we use a variance decomposition method to measure the contribution degree of pure technical efficiency and scale efficiency to comprehensive efficiency, the results of which are presented in Table 2. It can be seen from the results in Table 2 that, during 2003-2008, the mean of the contribution degree of pure technical efficiency on urban comprehensive efficiency was 0.72 , which is much higher than the contribution degree of scale efficiency on urban comprehensive efficiency, which was 0.28 , which is indicative of the fact that the changes in pure technical efficiency having emerged in this study period can be considered as the dominating ones if compared with the change of urban comprehensive efficiency. In 2009, the contribution of scale efficiency dropped to 0.13 , indicating that the decline in pure technical efficiency is the primary cause of the decline in urban comprehensive efficiency in that year. The biggest change in the period 2010-2012 was the one related to the rising of the mean of the contribution of scale efficiency to 0.44 . It indicates that the cities which are at or above the prefecture level in China, on condition that the technical level is roughly the same, are experiencing an increasing impact of the urban development scale on urban efficiency.

\section{An analysis of the characteristics of regional differences}

There are significant differences in regional development in China. So, this paper is based on the traditional three-area dividing method, by which the cities are divided into eastern, central and western, and these three zones are the subject matter of the study. The study finds that, similarly to the economic development of the three zones, for each year between 2003 and 2012, the mean of the three zones of urban efficiency showing the eastern, the central and the western "ladder" - types was descending (Figure 2). In the period 2003-2012, the mean of the urban efficiency of the eastern zone was 0.45 ; the mean of the urban

Table 2 The variance decomposition of urban comprehensive efficiency

\begin{tabular}{l|llllllllll}
\hline & 2003 & 2004 & 2005 & 2006 & 2007 & 2008 & 2009 & 2010 & 2011 & 2012 \\
\hline Pure Technical Efficiency & 0.76 & 0.70 & 0.66 & 0.74 & 0.74 & 0.67 & 0.86 & 0.59 & 0.55 & 0.52 \\
Scale Efficiency & 0.24 & 0.30 & 0.33 & 0.26 & 0.26 & 0.32 & 0.13 & 0.40 & 0.44 & 0.47 \\
\hline
\end{tabular}




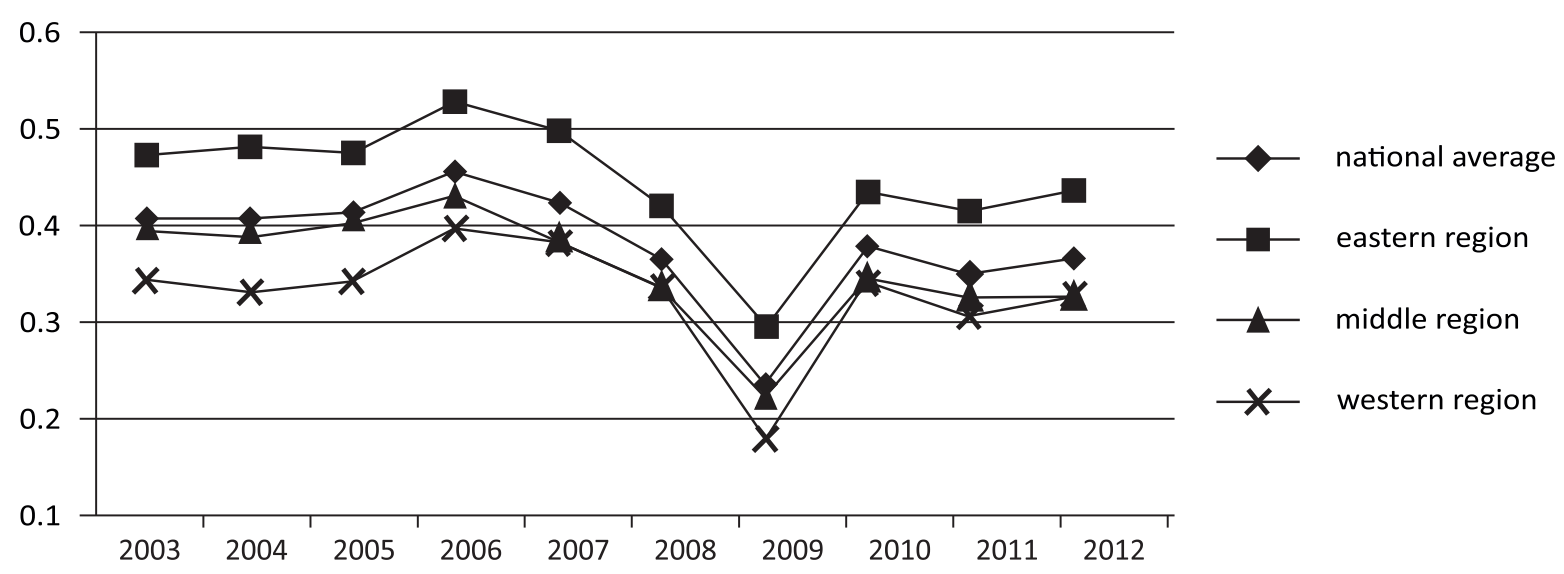

Figure 2 The zoning of the trend of change in China's urban efficiency

Source: Authors

efficiency of the central zone was 0.36 ; the mean of the urban efficiency of the western zone was 0.33 , and their ratio was $1.36: 1.09: 1$, respectively. Amongst the three zones, only the eastern region's urban efficiency was higher than the national average, with the average efficiency of the central and the western cities being all below the national average.

As can be seen when pure technical efficiency of decomposition is concerned, the distribution of urban pure technical efficiency in the three major areas of our country subverts the traditional "ladder-type" decline law, showing that the eastern urban pure technical efficiency was the highest, only to be followed by the western region, and was the lowest in the middle region. The specific values are $0.51,0.50$ and 0.45 in the eastern, the western and the central regions, respectively (Figure 3). During the period 2003-2007, the trend were fluctuating, showing a slight growth in the eastern region, while the middle region remained

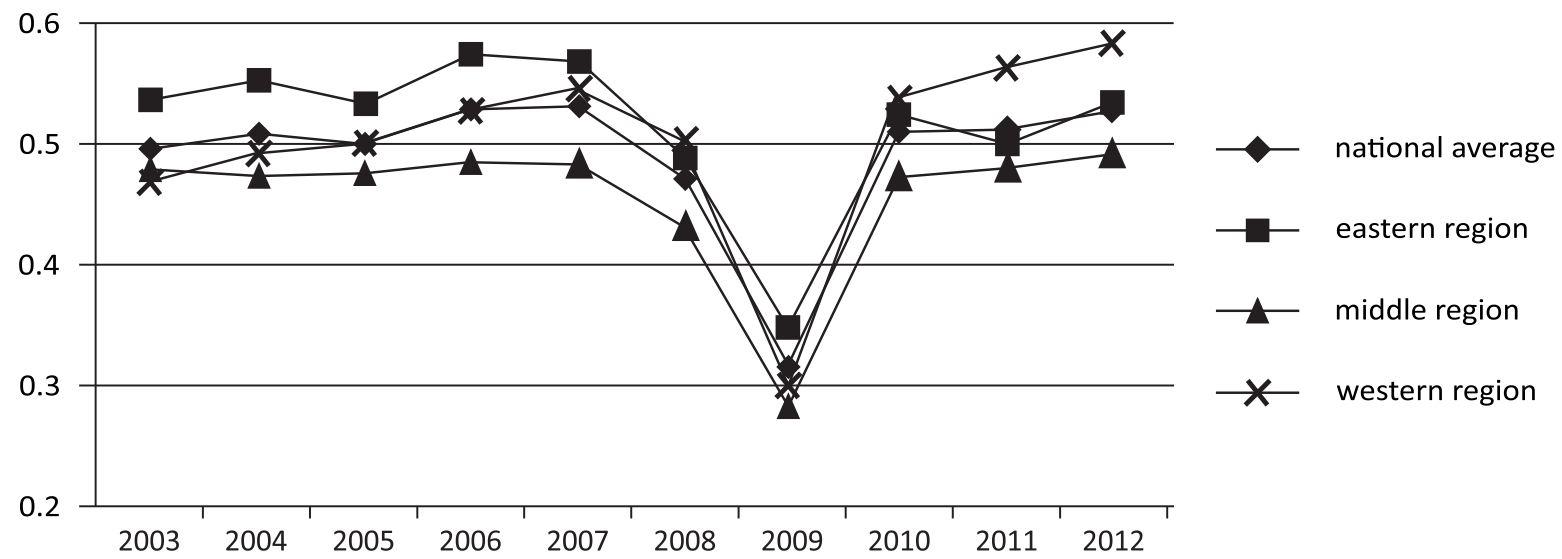

Figure 3 The zoning of the trend of change in China's urban pure technical efficiency 
at the same level of growth, and the western region continued to show a steady growth, exceeding the national average in 2005; during the period 2008-2009, the three regions showed a decline; during the period 2010-2012, the urban pure efficiency of the three regions rose and the growth of the western region exceeded that of the eastern region. This article explains this phenomenon on the fact that the western region, as an underdeveloped region in China, was in the process of economic development, although slightly restricted by their own fragile environmental issues, and paid more attention to the improvement of the technical level than the central region did; after the world economic crisis, the export volume of manufactured products fell, and Chinese labor costs increased, which led to the shifting of manufacturers inform the eastern region to the middle region and western region, bringing with them a more advanced production technology, so that the urban pure technical efficiency of the two regions improved.

As can be seen when scale efficiency is concerned, the average urban efficiency of the eastern, the central and the western regions was 0.86, 0.79 and 0.68 , respectively, which is the same as the distribution of urban comprehensive efficiency, showing it to be „high in the eastern region and low in the western region" (Figure 4). Regarding the trend of change, each one of the three regions showed a downward volatility trend, with the smallest decline in the eastern region, only to be followed by the central region, and the largest decline in the western region. This shows that, in the process of the rapid development of urbanization in our country, there is a rapid expansion of the size of the city, as well as a failure to allocate resources, a failure of the industrial scale to achieve the scale economy and other issues, too.

\section{A difference characteristic analysis of different scales}

In the process of urban development, different cities have different initial endowments, such as natural resources, the level of economic development, resulting in the cities' showing different scale characteristics. Therefore, according to the municipal district population size which counts $<500000$ people, 500000-1000000 people, 1-5 million people, or 5-10 million people, $>10$ million people, these cities are, in this paper, classified into five classes, namely small and medium-sized cities, big cities, megalopolises and super cities. Urban comprehensive efficiency and its decomposition results are shown in Table 3.

From the pure technical efficiency point of view, the average pure technical efficiency of the super cities, the megalopolises, the big cities, medium cities and small cities is $0.84,0.72,0.49,0.44$ and 0.53 , respectively. The

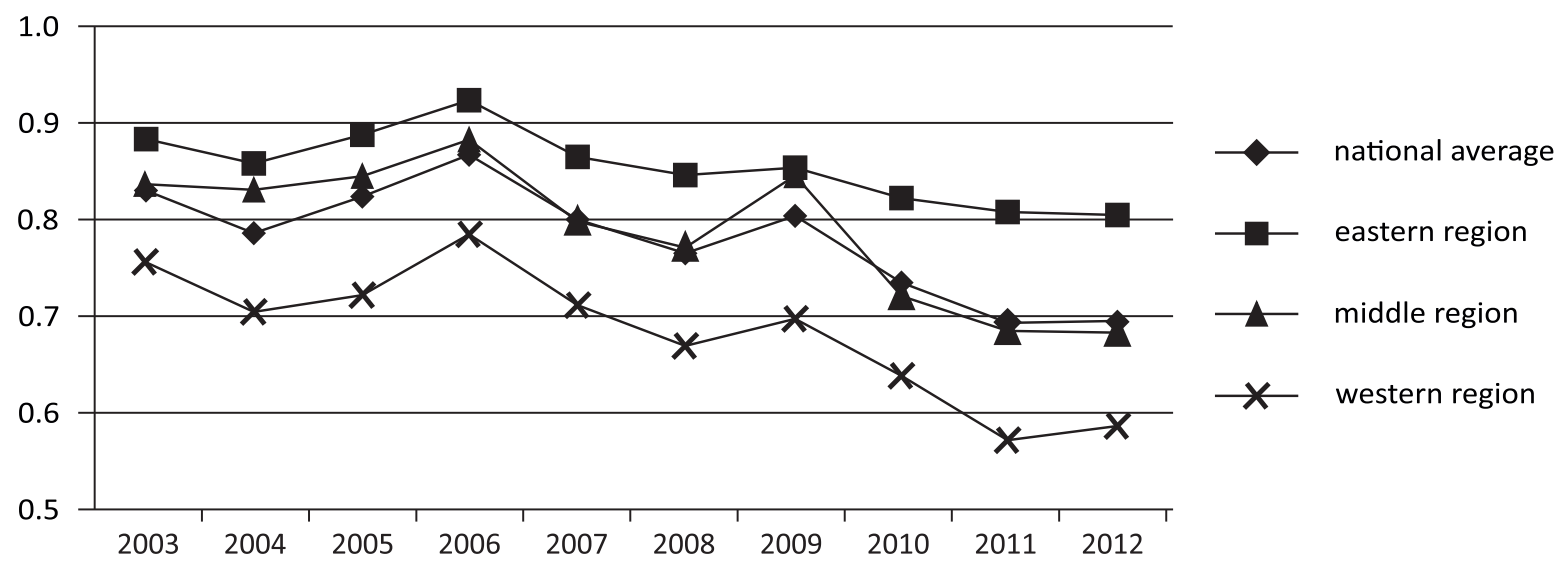

Figure 4 The zoning of the trend of change in China's urban scale efficiency 
Table 3 The Chinese urban efficiency and its decomposition, classified by size

\begin{tabular}{ll|lllllllllll}
\hline & City scale & 2003 & 2004 & 2005 & 2006 & 2007 & 2008 & 2009 & 2010 & 2011 & 2012 & Mean \\
\hline \multirow{6}{*}{ TE } & 0-500000 & 0.36 & 0.34 & 0.34 & 0.39 & 0.34 & 0.30 & 0.19 & 0.35 & 0.28 & 0.28 & 0.32 \\
& 500000-1000000 & 0.39 & 0.38 & 0.38 & 0.41 & 0.37 & 0.32 & 0.18 & 0.32 & 0.30 & 0.31 & 0.34 \\
& 1-5 million & 0.45 & 0.46 & 0.47 & 0.52 & 0.49 & 0.41 & 0.28 & 0.41 & 0.39 & 0.42 & 0.43 \\
& 5-10 million & 0.53 & 0.57 & 0.72 & 0.67 & 0.75 & 0.73 & 0.52 & 0.68 & 0.68 & 0.70 & 0.66 \\
& $>10$ million & 0.58 & 0.74 & 0.55 & 0.81 & 0.79 & 0.76 & 0.72 & 0.78 & 0.84 & 0.85 & 0.74 \\
\hline \multirow{6}{*}{ PTE } & 0-500000 & 0.53 & 0.51 & 0.52 & 0.53 & 0.54 & 0.51 & 0.36 & 0.60 & 0.59 & 0.62 & 0.53 \\
& 500000-1000000 & 0.46 & 0.47 & 0.45 & 0.48 & 0.48 & 0.43 & 0.23 & 0.47 & 0.47 & 0.48 & 0.44 \\
& 1-5 million & 0.49 & 0.52 & 0.52 & 0.55 & 0.55 & 0.47 & 0.32 & 0.48 & 0.48 & 0.51 & 0.49 \\
& 5-10 million & 0.70 & 0.69 & 0.73 & 0.76 & 0.76 & 0.75 & 0.69 & 0.70 & 0.69 & 0.70 & 0.72 \\
& $>10$ million & 0.76 & 0.77 & 0.79 & 0.82 & 0.81 & 0.80 & 0.81 & 0.83 & 1.00 & 1.00 & 0.84 \\
\hline \multirow{6}{*}{ SE } & 0-500000 & 0.70 & 0.66 & 0.67 & 0.75 & 0.64 & 0.59 & 0.66 & 0.57 & 0.49 & 0.48 & 0.62 \\
& 500000-1000000 & 0.84 & 0.81 & 0.84 & 0.87 & 0.77 & 0.75 & 0.84 & 0.69 & 0.65 & 0.65 & 0.77 \\
& 1-5 million & 0.91 & 0.89 & 0.91 & 0.94 & 0.89 & 0.86 & 0.85 & 0.83 & 0.81 & 0.81 & 0.87 \\
& 5-10 million & 0.83 & 0.84 & 0.98 & 0.91 & 0.98 & 0.96 & 0.70 & 0.97 & 0.97 & 0.99 & 0.91 \\
& $>10$ million & 0.80 & 0.91 & 0.73 & 0.97 & 0.97 & 0.90 & 0.78 & 0.90 & 0.84 & 0.85 & 0.86 \\
\hline
\end{tabular}

Source: Authors

average pure technical efficiency of the small cities is higher than that of the large and the medium-sized ones, but still lower than that of the super cities, the megalopolises. It can be concluded that the urban scale and pure technical efficiency represent the "U" - type change in China, that is to say with the expansion of the urban scale, pure technical efficiency declines at first, whereas the urban scale exceeds a certain size, pure technical efficiency gradually increases.

From the scale efficiency point of view, the bigger the size of a city, the higher the level of the urban scale efficiency of the city, increasing from 0.62 in the case of a small city to 0.91 of a megalopolis, but when super cities are concerned, urban scale efficiency declines even as low as to 0.86 , appearing to represent the "Inverted U" - type change. On the basis of the analysis of China's urban scale reward stage in Table 4, we can see that most of the cities in our country are still in a state of increasing their respective returns to the scale, with only a few cities which are in the state of constant returns to the scale or of decreasing returns to the scale. Given the fact that the majority of the cities are in the "growth" stage, a relative lack of investment is still the main reason hindering urban development.

The urban efficiency calculation results show that, during the period of our study, the averages of the urban efficiencies of the super cities, the megalopolises, the big cities, the medium cities and the small cities are $0.74,0.66,0.43,0.34$ and 0.32 , respectively. The rule according to which the larger the size of a city is, the higher its urban efficiency is, suggests that, during the period 2003-2012, the urban agglomeration effect that was driven by an urban expansion played a positive role in China's urban development. The larger urban development is, the higher the infrastructure construction level is; the more advanced scientific culture is, the bigger the aggregation of talents is, the higher the technology level and the management level of urban efficiency are. The greater the ability to attract investment is, the more obvious the urban industrial agglomeration effect is. Thus, urban efficiency and the urban scale show a gradual, step-by-step, growth.

As we can see from the relationship between comprehensive urban pure technical efficiency, scale 
Table 4 China's urban scale reward stage analysis

\begin{tabular}{l|cccccccccc}
\hline & 2003 & 2004 & 2005 & 2006 & 2007 & 2008 & 2009 & 2010 & 2011 & 2012 \\
\hline Increase & 247 & 241 & 247 & 233 & 248 & 249 & 168 & 248 & 252 & 252 \\
Constant & 23 & 28 & 27 & 31 & 29 & 26 & 26 & 27 & 22 & 24 \\
Decrease & 15 & 16 & 11 & 21 & 8 & 10 & 91 & 10 & 11 & 9 \\
\hline
\end{tabular}

Source: Authors

efficiency and changes in the urban size, the combined effect between the two opposite trends affects changes in the development of urban efficiency as well: before urban pure technical efficiency has reached the minimum level, with an increase in the city scale, pure technical efficiency declines; after having exceeded the inflection point, urban pure technical efficiency increases; before urban scale efficiency has declined, an increase in the city scale generates an increase in urban scale efficiency, and scale efficiency declines after it has gone beyond the inflection point. The mechanism of the action is crucial to the study of the city scale in China. It can clearly be concluded that, in the future process of the development of cities, and through a reasonable control of the city scale, the goals of increasing both urban pure technical efficiency and scale efficiency and of having urban efficiency more effectively improved in the future can be achieved.

\section{CONCLUSION}

In this paper, by constructing the SBM-Undesirable Model, which contains the undesirable output, the urban efficiency of the 285 cities either at or above the prefecture level in China during the period 20032012 is measured and changes in urban efficiency in China are analyzed. Having it decomposed into urban pure technical efficiency and urban scale efficiency, from the perspective of regional differences and scale differences that have been analyzed, the following conclusions can be drawn:

First, during the study period, the average level of urban efficiency is low; during the study period, the average efficiency is low in our country, and has the characteristics of an extensive urban development and a waste of resources. As we can see from the decomposition changes of efficiency, urban scale efficiency $>$ urban pure technical efficiency $>$ urban comprehensive efficiency on the whole, and the impact of urban scale efficiency on urban technical efficiency gradually increases, thus improving urban scale efficiency, which plays a key role in improving urban comprehensive efficiency.

Second, urban comprehensive efficiency between the three major areas in China represents the diminishing distribution of the eastern, the central and the western "ladder-types", and this pattern is consistent with the level of economic development in our country. The distribution pattern of urban pure technical efficiency appears to undergo new changes: urban pure technical efficiency is the highest in the eastern region, only to be followed by the western region, whereas the central region is at the lowest level. The distribution of urban scale efficiency and urban comprehensive efficiency is the same, and the scale efficiency of the western region reveals a large gap between the eastern and the central regions.

Third, from the point of the urban scale, urban comprehensive efficiency and the city scale represent a linear relationship, which means that, with the expansion of the city scale, urban comprehensive efficiency becomes higher. Further decomposed, it can be found that there are two opposite directions of the trend of change between urban pure technical efficiency, urban scale efficiency and the city scale, the results of which provide a new perspective and ideas for a research into the optimal scale of our country.

Based on the foregoing findings, this paper recommends that, in order to improve the urban efficiency of our country, we should develop different urban development strategies which are based on different regional characteristics of each city and 
the status of scale differences. In terms of regional differences, many cities in the middle and the western regions are in a stage in which returns to the scale are increasing, and restricted by scale efficiency, we should guide investment inflows, accelerate the construction of the infrastructure, rationally adjust the industrial layout and promote its scale efficiency. The cities in eastern region are in a stage in which returns to the scale are decreasing, which calls for a reasonable control of the city scale as a top priority in order to improve urban comprehensive efficiency.

In this paper, we use the SBM model to estimate the urban efficiency of the 285 cities which are at or above the prefecture level in China, verifying the initial idea: in consideration of the environmental factors, China's urban efficiency decreased significantly. This article, however, is still inadequate: the indicators used to measure the environmental factors, only using the discharge amount of industrial waste water and industrial gas, are obviously one-sided, which invites other scholars to improve it in the future.

\section{REFERENCES}

Alonso, W. (1971). The Economics of urban size. Papers in Regional Science, 26(1), 71-83. doi: 10.1111/j.1435-5597.1971. tb01493.x

Byrnes, P. E., \& Storbeck, J. E. (2000). Efficiency Gains from Regionalization: Economic Development in China Revisited. Socio-Economic Planning Science, 34(2), 141-1054. doi:10.1016/ S0038-0121(99)00022-1

Charnes, A., Cooper, W. W., \& Li, S. (1989). Using Data Envelopment Analysis to Evaluate Efficiency in the Economic Performance of Chinese Cities. Socio-Economic Planning Science, 23(6), 325-344. doi:10.1016/0038-0121(89)90001-3

Dai Yong'an. (2010a). Empirical Research on the Chinese Urban Efficincy and its Influencing Factors. Shanghai Journal of Economics, 12,12-19.

Dai Yong'an. (2010b). The Efficiency and Determinants of China's Urbanization. The Journal of Quantitative \& Technical Economics, 12, 103-117+132.

Fu Juan, \& Sun Jiuwen. (2014). The Efficiency of Beijing Urban Growth Trajectory. Urban Problems, 8, 31-38.

Gao Chunliang. (2006). From 1998 to 2003: Empirical Research on Urban Technical Efficiency and Scale Efficiency in China. Shanghai Economic Review, 2006, 6, 36-42.

Li Bozhi. (1987). Preliminary Survey of the Urban Efficiency of Nanchang City. Journal of Jiangxi Normal University, 4, 115$121+128$.

Li Pei. (2007). The Efficiency and Disparity of Urban Economic Growth in China. The Journal of Quantitative \& Technical Economics, 7, 97-106.

Li Xun, Xu Xianxiang, \& Chen Haohui. (2005). Temporal and Spatial Changes of Urban Efficiency in the 1990s. Geographica Sinica, 4, 615-625. doi: 10.11821/xb200504010

Macmillan, W. D. (2005). The estimation and applications of multi-regional economic planning models using data envelopment analysis. Papers in Regional Science 60(1), 41-57. doi: 10.1111/j.1435-5597.1986.tb01015.x

Pan Jinghu, \& Yin Jun. (2012). Analysis on the Urban Development Efficiency of Cities at Prefecture Level or above in China Based on DEA-ESDA. Economic Geography, $12,53-60$.

Poveda, A. C. (2012). Estimating effectiveness of the control of violence and socio economic development in Colombia: an application of dynamic data envelopment analysis and data panel approach. Social indicators research, 105(3), 343-366. doi:10.1007/s11205-010-9772-7

Prud'home, R., \& Lee, C-W. (1999). Size, Sprawl, Speed and the Efficiency of Cities. Urban Studies, 36(11), 1849-1858.

Shan Haojie. (2008). Reestimating the Capital Stock of China:1952-2006. The Journal of Quantitative \& Technical Economics, 10, 17-31.

Staničková, M., \& Skokan, K. (2012). Evaluation of the EU member states efficiency by data envelopment analysis method. Journal of Mathematical Models and Methods, 6(2), 349-357.

Syrjänen, M. J. (2004). Non-discretionary and discretionary factors and scale in data envelopment analysis. European Journal of Operational Research, 158(1), 20-33. doi:10.1016/ S0377-2217(03)00362-X

Wang Sijun. (1994). The Impact of Urban Efficiency Difference on China's future urbanization. Economic Geography, 1, 4652.

Young, A. (2000). Gold into Base Metals Productivity Growth in the People's Republic of China during the Reform Period. NBER Working Paper No 7856. doi:10.3386/w7856

Yuan Xiaoling, Zhang Baoshan, \& Zhang Xiaoni. (2008). 
Evolution Characters of China's Cities Based on The Superefficient DEA. Urban Studies, 06, 102-107.

Zhang Juntao, \& Liu Jianguo. (2011). Urban Efficiency and Its Spillover Effects-Based on the Analysis of 34 Cities in Northeeast China. Economic Geography, 4, 578-583+590.
Zhao Xiaoxia, Qu Aixue, Xun Wenhua, \& He Leilei (2012). Progress and Prospect of Study on City Efficiency. Journal of Huaihai Institute of Technology, 1, 74-78.

China City Statistical Yearbook

\title{
Received on $10^{\text {th }}$ July 2015 , after two revisions, accepted for publication on $17^{\text {th }}$ August 2015. \\ Published online on $25^{\text {th }}$ August 2015.
}

Yuan Xiaoling is a Professor and a Doctoral Tutor at Xi'an Jiaotong University. She is devoted to doing research into urban economics and regional economics.

He Bin is a postgraduate at Xi'an Jiaotong University. He is devoted to doing research into urban economics.

\section{EVALUACIONA ANALIZA URBANE EFIKASNOSTI U KINI RESPEKTUJUĆI EKOLOŠKA OGR ANIČENJA}

\author{
Yuan Xiaoling i He Bin \\ School of Finance and Economics of Xi'an Jiao Tong University, Xi'an, Shaanxi, China
}

\begin{abstract}
S obzirom na to da postojeća srednjoročna i dugoročna evaluacija i analiza urbane efikasnosti zanemaruju spoljašnje negativne učinke na okruženje, ovaj rad ima za cilj da konstruiše SBM model koji obuhvata i nepoželjne rezultate, meri urbanu efikasnost u 285 gradova, na nivou prefekture ili iznad tog nivoa, u Kini, u periodu 2003-2012, razloži je na urbanu čisto tehničku efikasnost i urbanu efikasnost obima, i sprovede odvojene komparativne analize svake od njih. Rezultati pokazuju da je, uzimajući u obzir ekološke faktore, urbana efikasnost u Kini na niskom nivou, i da postoji veliki prostor da se ona unapredi. Urbana efikasnost obima ima stalni, sve snažniji uticaj na urbanu efikasnost. Iz regionalne perspektive, urbana čisto tehnička efikasnost je na najvišem nivou u istočnom regionu, zatim, na nešto nižem nivou u zapadnom regionu, dok je u srednjem regionu na najnižem nivou. Urbana čisto tehnička efikasnost predstavlja promenu „U“ tipa, a urbana efikasnost obima predstavlja „obrnutu U“ promenu. Iz tog razloga, da bi se urbana efikasnost poboljšala, predlaže se usvajanje različitih politika urbanog razvoja u gradovima koji se nalaze u različitim regionima i koji su različitih veličina.
\end{abstract}

Ključne reči: urbana efikasnost, SBM model, analiza razlika 